\title{
Alkohola edatearen eragina garun nerabean
}

\section{(Alcohol drinking consequences on the adolescent brain)}

\author{
Amaia Nuñez-delMoral*, Luis F. Callado \\ Farmakologia Saila (UPV/EHU) eta \\ Centro de Investigación Biomédica en Red de Salud Mental (CIBERSAM)
}

LABURPENA: Jakina da gure gizartean alkoholaren kontsumoa oso hedatuta eta onartuta dagoela; eta horren gehiegizko kontsumoak eragin ekonomikoak, sozialak eta osasunekoak ditu. Gehienetan alkoholaren lehendabiziko kontsumoa nerabezaroan gertatzen da. Jakinda garun nerabea heltzen ari den organoa dela, argi dago alkoholaren kontsumoak eraginak dituela haren garapenean. Haren ezaugarri biologikoak direla eta, garun nerabeak ez du gaitasun nahikoa ekintzen ondorioak aurreikusteko, eta horrek handitu egiten du alkoholaz gain beste droga batzuk gehiegi kontsumitzeko arriskua. Beraz, beharrezkoa egiten da nerabeei ezagutaraztea zeintzuk diren alkohola edatearen eragin kaltegarriak, beren kontsumo patroia alda dezaten. Horretarako, lan honetan alkoholaren gehiegizko kontsumoak garun helduan dituen eraginak azaltzen hasten gara, eta garun nerabean dituen eraginak azalduz amaituko dugu, tartean garun nerabeak dituen hainbat ezaugarri aipatuz.

HITZ GAKOAK: Alkohola, garun-nerabea, garun-heldua.

ABSTRACT: Alcohol consumption is very accepted and highly developed in our society; and its overconsume has economic, social and health consequences. In most cases the onset of consumption occurs during adolescence. Since, the brain is an organ that is still maturing, it is clear that alcohol consumption has consequences for its development. Due to its biological characteristics, the adolescent brain is not able to foresee the consequences of an action. This increases the risk for consumption of alcohol and other addictive substances. Therefore, it is necessary to make adolescents aware of the harmful consequences of excessive alcohol consumption, so that they can change their consumption pattern. For this purpose, in the present work we begin explaining the consequences of excessive alcohol consumption in the adult brain, and some characteristics of the adolescent brain, to end with the consequences of drinking in the adolescent brain.

KEYWORDS: Alcohol, adult brain, adolescent brain.

\footnotetext{
* Harremanetan jartzeko / Corresponding author: Amaia Nuñez-delMoral. Farmakologia Saila (UPV/EHU), Bizkaiko Kanpusa, Sarriena Auzoa, z/g, 48940 Leioa (Bizkaia). - amaia.nunez@ehu.eus - https://orcid.org/0000-0002-1749-7055.

Nola aipatu / How to cite: Nuñez-delMoral, Amaia; Callado, Luis F. (2020). «Alkohola edatearen eragina garun nerabean»; Ekaia, 38, 2020, 41-53. (https://doi.org/10.1387/ekaia.21785).

Jasoa: 03 ekaina, 2020; Onartua: 17 uztaila, 2020.

ISSN 0214-9001 - elSSN 2444-3255 / (c) 2020 UPV/EHU
}

(c) (i) (0) Obra hau Creative Commons Atribución 4.0 Internacional-en

lizentziapean dago 


\section{SARRERA}

Alkohola edateak urtero 3 milioi heriotzetan eta gaixotasunen $\% 5$,1 ean parte hartzen du mundu osoan [1]; baina hain da handia alkohola kontsumitzeko ohitura, ezen, askotan, horrek eragiten dituen kalteak oharkabean pasatzen baitira. Beste substantzien kontsumoarekin alderatuta, alkohola edatea oso hedatuta eta onartuta dago gure gizartean. Izan ere, 2017an Euskal Autonomi Erkidegoan (EAE) 1,5 milioi pertsonari egindako inkesta batek dio gizartearen ia \%77 edale soziala dela eta, harrigarria izan arren, \%13k eguneroko kontsumoa egiten duela. Gainera, gizartearen $\% 3,3 \mathrm{k}$ kontsumo arriskutsua egiten du, \%1,2k kontsumo kaltegarria eta $\% 0,2 \mathrm{k}$ alkoholarekiko menpekotasuna dauka [2]. Aipatzekoa da, halaber, alkohola edaten hasteko adina. Populazioaren $\% 31,7 \mathrm{k} 15$ urte edo gutxiago zituen lehen aldiz edan zuenean, eta hortik gertu, \%31,9k 16-17 urte zituen kontsumitzen hasi zenean. 18 urtetik gorako kontsumitzeko hasiera, ordea, \%29,6an izan zen [2].

Honekin lotuta, interesgarria da 2010. urtean David Nutt ikertzaileak aurkeztu zuen lana Erresuma Batuko drogen kalteen inguruan. Han, alkoholaren kontsumoa heroinarena baino kaltegarriagoa dela erakusten du. Nahiz eta harrigarria dirudien, azalpena dauka; izan ere, Nuttek kontuan izan zuen drogaren kontsumoaren ondorioak besteengan eta ez bakarrik kontsumitzailearengan. Horien artean, trafiko-istripuak, indarkeria, infekzioen transmisioa, krimenak, adingabeen abandonua... [3] Heroina oso kaltegarria da kontsumitzen duenarentzat, noski. Baina, faktore guztiak batuta (ekonomikoak, sozialak eta osasunari dagozkionak) oro har alkohola edatearen ondorioak larriagoak dira gure gizartearentzat.

Horretaz gain, aipatu den bezala, kontsumoaren hasiera gehienbat nerabezaroan gertatzen da. Epe laburrean, alkoholaren kontsumoak nerabeengan sexu-harreman arriskutsuak eta istripuak izateko zein beste substantziak hartzeko arriskua handitzen du [4]. Epe luzean, ordea, beste gaitz edo gaixotasunak agertzeko arriskuarekin [5], arrakasta akademiko eskasarekin [6] eta funtzio neurokognitiboen kaltearekin lotzen da [7]. Bestalde, noizbehinka alkoholaren gehiegizko kontsumoa (binge drinking, ingelesez) egiten duten nerabeek (GN) askotan kontsumo-patroi bera mantentzen dute heldutasunera heltzen direnean [8]. Halaber, nerabezaroan ohiko gehiegizko alkoholaren kontsumoak (heavy drinkers) (GO) heldutasunean alkoholismoa eta harekin erlazionatutako gaitzak pairatzeko arriskua esanguratsuki handitzen du [9].

Argi dago, beraz, EAEn alkoholaren kontsumoa ikaragarri altua dela eta oso adin gaztean hasten dela, eta horrek ondorioak ditu. Lan honetan, gaur egun daukagun ebidentzia zientifikoaz baliatuz, alkoholaren kontsumoak garun nerabean eragiten dituen aldaketak azalduko dira. Horretarako, lehenik eta behin, etanolak garun helduan dituen eraginak azalduko dira, eta garun nerabearen ezaugarri garrantzitsuenak ere aipatuko dira. 


\section{ALKOHOLAREN ERAGINA GARUN HELDUAN}

Alkohol etilikoa edo etanola nerbio-sistema zentralaren depresorea da. Beraz, alkohola edateak eragin neurotoxikoak izango ditu garunean (batzuk, larriak): eragin horiek kontsumitzailearen portaera edota zenbait funtzio biologiko aldatzen dituzte [10]. Hala nola, depresio psikomotorra, informazioa gordetzeko eta arrazoibide logikoa egiteko zailtasuna, nortasun-aldaketak, koordinazio-motorraren murrizpena eta sari-sistemaren kitzikadura ager daitezke, azken hori adikzioaren garapenarekin lotutako faktorea $[10,11]$.

Beste drogek ez bezala, alkoholak ez du berariazko iturik gure organismoan [12]. Ondorioz, gure garunean eragiteko erabiltzen dituen mekanismo zehatzak ezezagunak dira oraindik. Hala ere, jakin badakigu zenbait hartzailerekin zuzenean elkar eragiten duela $[12,13]$. Alde batetik, $\mathrm{GABA}_{\mathrm{A}}$ hartzailea kitzikatzen du GABA neurotransmisorearen efektu inhibitzaileak indartuz, eta ondorioz, alkohola edatean sedazioa eta erlaxazioa agertzen dira [13]. Eta, bestetik, glutamatoaren NMDA hartzailea inhibitzen du glutamatoaren efektuak ahulduz [12, 13]. Gainera, potasio ioiaren bi kanal moten aktibazioa handitzen du, eta serotoninaren hartzaile bat $\left(5 \mathrm{HT}_{3}\right)$, azetilkolinaren hartzaile nikotinikoa eta glizina hartzailea kitzikatzen ditu $[12,13]$. Azkenik, ematen du zeharkako mekanismoaz baliatzen dela bestelako neurotransmisore eta itu molekularrak modulatzeko: horien artean, sistema opioidea, dopaminergikoa, serotoninergikoa eta endokanabinoidea $[12,13]$.

Garunaren egitura makromolekularrari dagokionez, alkoholaren eragina nabarmenagoa da garunaren zenbait eremutan, hala nola bekoki-aurreko kortexean, sistema linbikoan eta zerebeloan. Alkohola edatearen ondorioz garun-atal kaltetuenetariko bat bekoki-aurreko kortexa (BAK) da. BAKa funtzio exekutatzaileen arduraduna da; hau da, zentzutasuna, arazoen konponbidea, erabakiak hartzea, planifikazioa, jarrera sozialak, emozioak eta pertsonalitatea, besteak beste [14]. Alkohola epe luzean kontsumitzeak BAKaren bolumenaren murrizpena, aktibitatearen aldaketa eta neuronen \%15-23aren hondamena ekar lezake [14]. Hortaz, alkoholikoek funtzio exekutatzaileen disfuntzioa erakusten dute [14, 15]. Ondorioz, lanarazoak, errendimendu akademiko baxuagoa edo kotxe-istripuak izateko arrisku altuagoa dute.

Bestalde, sistema linbikoak gorputzaren homeostasia, oroimena, ikastea eta emozioen pertzepzioak eta hauekiko jokabideak kontrolatzen ditu [16]. Hipokanpoa, amigdala eta hipotalamoa sistema linbikoaren atalak dira, eta horietan ere ikusi dira alkoholaren ondoriozko aldaketak $[14,16]$. Hipokanpoa berehalako eta epe luzeko oroimenen arduraduna da, eta alkoholaren kontsumo mantenduak haren bolumena, aktibitatea eta neurona berrien sorrera murrizten ditu $[14,17]$. Ondorioz, alkoholismoa pairatzen duten 
pertsonetan nabaria da oroimen berriak sortzeko gaitasun falta, epe luzeko oroimena mantentzen den arren [10]. Amigdalak emozioen kontrola dauka; hau da, antsietatea, agresibitatea, beldurra, amodioa, oroimen emozionala eta bestelako emozioak erregulatzen ditu [16, 17]. Hipokanpoarekin batera amigdalak ere bere bolumenaren eta aktibitatearen murrizpena jasaten du alkohola edatearen ondorioz $[14,18]$. Egitura aldaketa hori edateko desioarekin eta alkohola berriro kontsumitzeko arriskuaren handitzearekin lotu da edateari utzi dioten pertsonetan, emozioen kontrol gabeziagatik, alegia [18]. Hipotalamoaren funtzioen artean gorputz-tenperatura, gosea eta egarria, loaldia (erritmo zirkadianoa) eta oreka hormonalaren erregulazioa daude [16]. Beraz, alkoholaren kontsumoa denboran zehar mantentzeak gaitasun horien guztien desoreka eta disfuntzioa eragiten du [11]. Aipatutako funtzioez gain, hipotalamoak beste garun atalekin sortzen dituen konexioak oroimen- eta ikaste-prozesuetan parte hartzen dute, eta alkohola edateak epe luzean hipotalamoaren egitura kaltetzen du; horrek, informazio berria gordetzeko ezintasuna eta aspaldiko gertaeren galtzea eragiten du [14]. Hipotalamoaren mamila-gorputzak, adibidez, hipokanpoaren informazioa jasotzen dute, eta prozesatu ondoren sistema linbikoaren beste egitura batzuetara bidaltzen du, eta berriro hipokanpora bueltatzen da erantzun bat emateko [19]. Informazioaren garraiobide hori Papez-en zirkuitua da eta horren bidez mamila-gorputzek jarrera afektiboetan eta ikaste-prozesuetan parte hartzen dute [19]. Alkoholaren kontsumoaren ondorioz, mamila-gorputzen bolumena murrizten da, eta hori lotuta egon daiteke alkoholikoetan agertzen den ikasteko zailtasunarekin eta oroimen episodikoaren galerarekin [20].

Azkenik, zerebeloaren egituran ere aldaketak deskribatu dira. Zerebeloa mugimendu motorren koordinaziorako oinarrizko atala da [21]. Baina horretaz gain, azkenengo urteotan adikzioen garapenean eta mantentzean funtsezko papera duela ikusi da [22]. Zerebeloak drogen kontsumoarekin lotutako oroimenen finkatzean parte hartzen du, eta, beraz, droga ikustean sortzen den hartzeko beharraren erantzunean ere bai [15, 22]. Garun atal horretan, alkoholikoek gai grisaren bolumena murriztuta daukate, eta hori erlazionatuta egon daiteke bai alkohola edatearen kontrol gabeziarekin, bai koordinazio muskularraren galerarekin [11,23].

Garuneko aldaketa horiek guztiek menpekotasuna indartzen dute. Izan ere, alkohola epe luzean kontsumitzean hainbeste aldaketa izan dira, non garunak ez baitu jadanik behar bezala funtzionatzen edan gabe eta kontsumoa etetean abstinentzia-sindromea agertzen baita, aipatutako garun-funtzio galera guztiekin [11]. Gainera, tolerantzia deritzon moldaketa neuronala ere gertatzen da. Horretan, zenbat eta gehiago edan (kantitatean eta denboran), orduan eta alkohol kantitate handiagoak behar dira hasieran zeuden efektu indartzaileak lortzeko. Tolerantziaren ondorioz, alkoholikoek edaten duten etanol kantitateak handituz doaz, eta edateari uztean 
abstinentzia-sindromea jasaten dute [15]. Beraz, gerta liteke sintomatologia hori saihesteko nahian edateari utzi dion alkoholiko batek berriro alkohola edatea, eta alkoholikoa menpekotasunaren gurpil zorotik atera ezinik geratzen da [24].

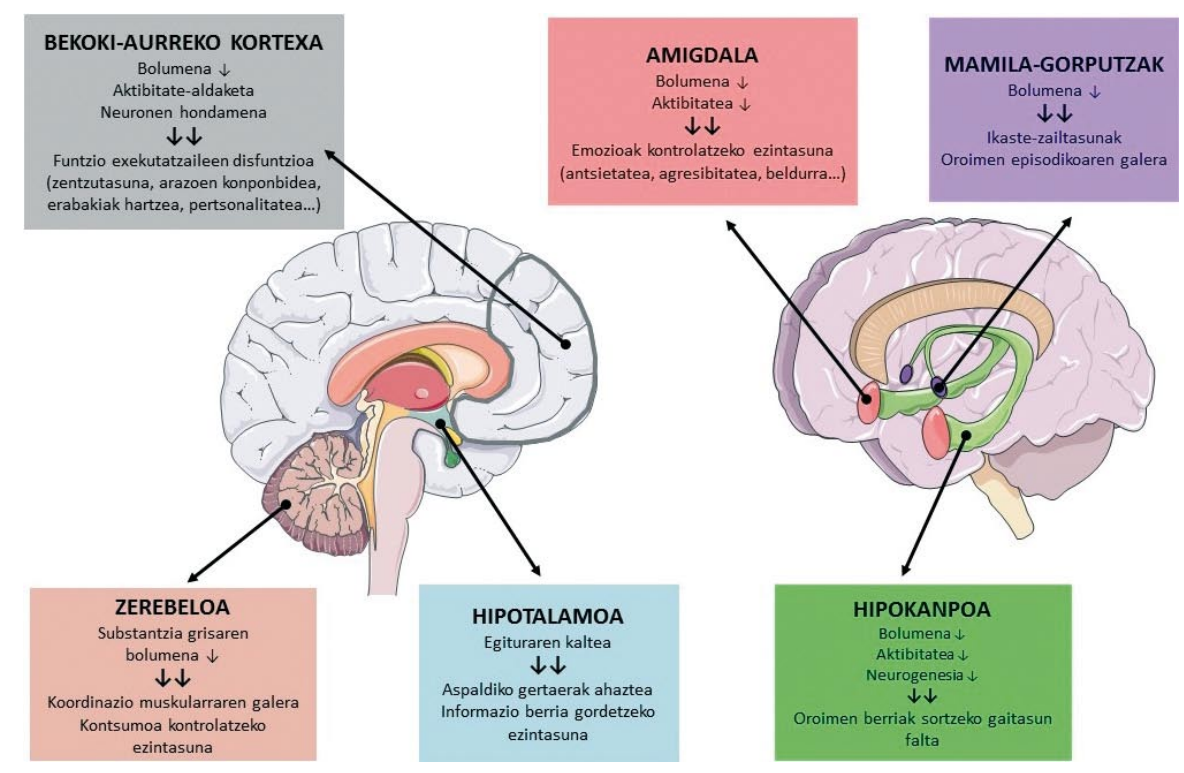

1. irudia. Garun helduan alkoholak eragindako aldaketen irudi eskematikoa (garunaren marrazkiak Servier Medical Art-etik hartu eta eraldatu dira (http://smart. servier.com/) Creative Commons Attribution 3.0 Unported (CC BY 3.0) baldintzei jarraituz).

\section{ALKOHOLAREN ERAGINA GARUN NERABEAN}

Haurtzarotik heldutasunera igarotzeko prozesuan, nerabezaroa deituriko tartea dugu erdian, zeinetan besteenganako menpekotasuna izatetik nolabaiteko independentzia lortzea baitugu helburu. Nerabezaroan, aldaketa hormonalez eta fisikoez gain, aldaketa neuralak, kognitiboak eta jarrera-aldaketak ere gertatzen dira [25]. Jarrera-aldaketen artean, erabaki arriskutsuak hartzeko joera eta sentsazio berriak bilatzea daude; horien artean, alkohola edo bestelako substantziak hartzen hastea [26].

Pubertaroan, garuna, beste organo batzuk bezala, helduz doa. Heltzeprozesuan garunak aldaketa neuronal garrantzitsuak jasaten ditu: gutxigora behera 22-25 urte izan arte jarraitzen dute aldaketok [27]. Hau da, nerabezaroan dugun garuna ez da heldutasunean izango dugun garun bera. Era 
berean, alkoholak ez ditu eragin berak bietan, noski. Alkoholaren kontsumoaren ondorioz gertatzen diren aldaketak azaldu aurretik, beharrezkoa da garun nerabearen ezaugarri garrantzitsu batzuk aurkeztea.

\subsection{Garun nerabearen ezaugarriak}

Nerabezaroan inauste sinaptikoa izeneko prozesua gertatzen/izaten da. Horretan, sinapsi ahulen mozketaren eta zelulaz kanpoko matrizearen aldaketaren ondorioz gai grisaren bolumenaren murrizpena gertatzen da. Era horretan, konexio neuronal garrantzitsuenak eta eraginkorrenak gogortzen dira eta deusezta daitezkeenak ezabatu, eta garun heldua bizi izan ditugun esperientzietara moldatutako garuna izango da [27, 28, 29, 30]. Aldi berean, gai zuriaren garapena gertatzen da; hau da, neuronen axoiek mielinizazioa jasaten dute, informazio garraioaren abiadura handitu dadin eta garun atalen arteko konexioak garatu daitezen [31, 32].

Garunaren nerabe garaia arrisku-jarrerak handitzen diren garaia ere bada. Gainera, harreman sozialek garrantzi handia dute nerabeengan. Maila soziala mantentzeko, erabaki arriskutsuak hartzeko jarrerek are eta indar handiagoa hartzen dute nerabezaroan, eta jarrera arriskutsuen artean alkoholaren kontsumoa dago; izan ere, jakin badakigu ingurugiro sozialak eragin handia duela gaztaroan alkohola hartzearekin [31, 33]. Heldu-aroan, ordea, normalean ez da harreman sozialen eta jarrera arriskutsuak hartzeko jarreren arteko erlazio hori ikusten [33]. Erabaki arriskutsuak hartzeko joera hori lotu da, alde batetik, BAKaren heldutasun faltarekin; eta bestetik, sistema linbikoaren aurretiko heldutasuna lortzearekin [35]. BAKak funtzio exekutatzaileak kontrolatzen ditu (horien artean, erantzunen inhibizioa), eta sistema linbikoa funtsezkoa da emozio- eta sari-estimuluen prozesamenduan $[14,16]$. Lehenengoaren eta bigarrenaren arteko desorekak emozioen kontrolaren eta horiei ematen zaien erantzunaren inhibizio gabezia eragiten du [29]. Eta, beraz, emozioekin lotutako erabakiak edo erabaki arriskutsuak hartzeko joera [35]. Gainera, nerabezaroan sari-sistemaren hainbat konexio neuronal bereziki aktibatuta daude [36]; hori uler daiteke garun gazteetan inauste sinaptikoa oraindik gertatu ez delako, eta, ondorioz, garun helduekin alderatuta inhibizio-maila txikiagoa delako [26]. Sariak eskuratzean, sari-sistemaren zirkuitu neuronalak aktibatuagoak daude nerabeetan helduetan baino; saria eskuratzearen aurreikuspenean, berriz, nerabeek aktibazio txikiagoa dute [37]. Beste era batean esanda, heldu arte, nerabeek gertaerak aurreikusteko gaitasuna ez dute behar bezala garatzen, eta, aurrekoarekin batera, erabaki desegokiak hartzeko arrisku handiagoa dute.

\subsection{Alkoholaren eraginak garun nerabean}

Nerabezaroan alkohola kontsumitu dutenen eta kontsumitu ez dutenen artean ezberdintasun kognitiboak agertzen dira. Lehenengoek erabaki arris- 
kutsuak hartzeko joera handiagoa daukate; eta lanerako oroimena, hainbat funtzio exekutatzaile eta espazio-ikusmenaren arreta-gaitasuna, ordea, murriztuta dauzkate $[26,38]$. Aditza ikasteko eta oroimenerako gaitasunen murrizketa gertatzen da, alkoholaren dosiaren arabera [26]. Alkohola kontsumitzeari uzten bazaio, gaitasun horiek berreskuratzea posiblea den ez dakigu oraindik [26]. Ikerketa batzuek iradokitzen dute nolabaiteko berreskurapena dagoela; besta batzuek, ordea, ez. Hala ere, ematen du heldutasunean funtzioen galera mantentzen dela desintoxikatu diren pertsonetan [38]. Beraz, alkoholaren kontsumo goiztiarra, nerabezaroan, izan daiteke aipatutako defizit kognitiboen jatorria helduengan.

Aipatu den bezala, alkohola kontsumitzen ez dutenekin alderatuta, nerabe kontsumitzaileen garunak ezberdintasunak aurkezten dituztela ikusi da erresonantzia magnetiko bidezko irudietan (ingelesez, magnetic resonance imaging, MRI) [7, 29]. Alde batetik, gai grisaren bolumena txikiagoa da hurrengo garun ataletan: BAKean, garun-azal parietal eta tenporaletan, zerebeloaren, hipokanpoaren eta zenbait garun atal linbikotan. Eta bestetik, gai zuriaren integritatea eta efizientzia txikiagotuak daude [7, 26, 38]. Garun-aldaketa nabarienak noizbehinkako kontsumoa egitetik GOra (gehiegizkoa eta ohikoa) izatera igarotzen duten nerabeetan gertatzen dira [38]. Alabaina, kontsumo larrira heltzen ez diren horietan ere, gai grisaren garapena kaltetuta dago, honako funtzio hauek betetzen dituzten garun-azaleko ataletan: funtzio exekutatzaileak, kontrol kognitiboa, arreta, integrazio sentsoriala eta hizkuntzaren prozesamendua [40]. Gainera, alkohola edatearen ondorioz inauste-sinaptikoa moteldu egiten da, eta, beraz, gai grisaren garapena ez da behar bezala gertatzen [26].

Nerabezaroan kontsumitzearen eraginak gai zurian ere agertzen dira. Garai horretan, gai zuria garatzen ari da, eta haren bolumena handitzen [31]. Alkoholak, ordea, handitze hori ahuldu egiten du eta gai zuriaren integritatea kaltetuta agertzen da [40]. Hala ere, ezin da ezarri deskribatutako aldaketen kausa bakarra alkoholaren kontsumoa dela; izan ere, gazte asko alkohola kontsumitzen hasten direnean beste mota batzuetako substantziak ere kontsumitzen hasten dira (esate baterako, kalamua edo tabakoa), eta, ondorioz, ezinezkoa da bakoitzaren eragina zein den zehaztea [26]. Hurrengo bi ikerketatan, ordean, alkoholaren eta kalamuaren eraginak bereiztea lortu dute: alde batetik, Bavka eta haren lankideek (2013) egindako ikerketan ikusi dute gai zuriaren integritatean agertzen diren aldaketak erlazioa dutela alkoholaren erabilerarekin bakarrik eta ez kalamuarenarekin [31], eta, bestetik, Jacobus eta Tapertek (2013) deskribatzen dute gai zuriaren integritatearen murrizpena gertatzen dela alkohola eta kalamua hartzen duten nerabeengan, baina alkoholak badaukala aparteko eta dosiaren menpeko eragin esanguratsuak gai zurian [7].

MRI funtzionalaren (fMRI) teknika batek odolaren oxigenazio-mailen seinalea neurtzen du; honek aktibitate neuralaren informazioa ematen du, 
eta estimulu baten ondorioz sortzen den erantzunaren aktibitatea neurtu eta konparatu ere egin daiteke. fMRIren bidez ikusi da garunaren aktibazioa ezberdina dela alkoholaren kontsumitzaileengan zeregin kognitibo bat egiten duten bitartean, nahiz eta zereginaren etekina ez den esanguratsuki aldatzen [41, 42]. Dena den, lehen aipatu den bezala, ezin da lotura zuzenik egin garun-aldaketen eta alkoholaren kontsumoaren artean, beste substantzia batzuen presentzia ohikoagatik [26]. Horretaz gain, deskribatu da alkoholaren kontsumo larria egin aurretik badagoela garun-azal frontalaren eta parietalaren (lanerako memorian inplikatutako garun-atalak) aktibazioaren murrizpena, kontsumo larrira inoiz helduko ez diren nerabeekin konparatuta [43]. Urte batzuk geroago, noizbehinkako kontsumoa egitetik kontsumo larria egitera heltzen badira, aipatutako garun-atalen gainaktibazioa ikusten da. Izan ere, alkoholaren kontsumitzaile larriek memoriaren prozesamendu egokia egiteko gaitasun falta erakusten dute; zailtasun horri aurre egiteko, aktibitate neuronala handitzen da, alegia [43]. Bestalde, GNetan zerebeloaren aktibitatea gutxituta dago; horrek iradokitzen du noizbehinkako alkoholaren kontsumo handiak sari- eta emozio-erantzunak murriztu ditzakeela [44].

Jokabide inpultsiboen kontrola funtzio exekutatzaileen alderdi garrantzitsuenetariko bat da, eta garrantzia hartzen du nerabezaroan. Horretaz gain, beste funtzio exekutatzaile garrantzitsu batzuk dira arreta selektiboa, lanerako oroimena (denbora tarte txikian informazio kantitate bati eusteko eta hura erabiltzeko gaitasuna) eta malgutasun kognitiboa (gertaera bat ikuspuntu ezberdinetatik ikusteko eta horretara moldatzeko gaitasuna) [45]. Jokabide inpultsiboak kontrolatzeko gaitasuna eta horretan parte hartzen duten prozesu neuralak murriztuta agertzen dira alkoholarekiko menpekotasuna pairatzen duten pertsonetan [46]. Joan/EzJoan (Go/NoGo, ingelesez) izeneko testak erabiltzen dira jokabide inpultsiboen kontrolean aktibatzen diren garun-atalak edo konexio neuronalak detektatzeko. Test horietan, GOei eta NTei (noizbehinka alkoholaren kantitate txikiak hartzen dituzten nerabeak) bi mota hauetako irudiak jartzen zaizkie: alkoholik gabeko edarienak ( «Joan» estimulua) eta alkoholdun edarienak («EzJoan» estimulua). Parte-hartzaileek «Joan» irudia ikusten dutenean palanka bati eman behar diote eta «EzJoan» ikusten dutenean, ordea, ez. Irudiak oso azkar aldatzen direnez, garunak funtzio exekutatzaileak erabiltzen ditu faltsujotzeak saihesteko. Eta, testa egiten den bitartean garunaren aktibitatea neur daiteke fMRIa erabiliz. GOek NTekin konparatuta faltsu-jotze gehiago dituzte, hau da, jarrera inpultsiboak kontrolatzeko gaitasuna murriztuta dute. Gainera, horien inhibizioa kontrolatzen duten garun-atalen gainaktibazioa ikusten da; kontrol faltaren aurrean garunak gainaktibazioarekin erantzuten $\mathrm{du}$, behar duen inhibizioa lortzeko [47]. Lanerako oroimenean antzeko zerbait gertatzen da. Hasieran, nerabeek kontsumo handira heldu ez direnean, aktibitate frontoparietal baxuagoa daukate kontrolekin alderatuta; baina, epe luzean kontsumo altua mantendu ondoren, zeregin bat betetzean GOek arreta handitu behar dute, kontrolek duten etekin bera lortzeko [43, 48]. 
GOetan ikaskuntzaren eta oroimenaren prozesuetan parte hartzen duten garun-atalen gainaktibazioa ere gertatzen da [38].

Sari-sistemari dagokionez, alkohola edatean (mendekotasuna sortzen duten beste substantziekin, sexuarekin, elikagaiekin gertatzen den bezala) bidezidor jakin batzuk aktibatzen dira, dopamina askatzen da eta plazera sentitzen dugu. Bidezidor hau aktibatzen da kontsumitzen den substantziaren edo haren kontsumoarekin erlazionatutako irudi bat ikustean ere [49]. Edari alkoholdunen irudien aurrean GOetan, NTekin konparatuta, sari-prozesamenduan parte hartzen duten garun-atal batzuen gainaktibazioa gertatzen dela ikusi da [50]. Hau da, alkoholarekin erlazionatutako estimuluen ondoriozko erantzuna handiagoa da GOetan. Bestalde, gainaktibazioa jaisten da, alkohola kontsumitzeari uzten bazaio [51]. Beraz, alkoholaren kontsumo handiak baditu eraginak nerabeen sari-prozesamenduan eta substantzia honekiko estimuluak ikusteak honen gehiegizko aktibazioa eragiten du, eta kontsumitzeko arriskua handiagotu [49].

Azkenengo urteetan, alkohola edan ondoren agertzen diren sintomek (ajea eta abstinentzia-sintomak) eragin neurotoxikoak dituztela ere ikusi da, eta sortzen duten neurotoxikotasuna alkohola berak eragiten duena baino kaltegarriagoa izan daiteke [7]. Oroitzapen berehalakoak eta berantiarrak berreskuratzeko eta ikaste-gaitasunen arazoak ajearen sintomen larritasunarekin lotuta daude; abstinentziaren sintomak, ordea, ikaste- eta oroimena-prozesuen galerarekin erlazionatu dira [7, 52].

Azkenik, aipatu beharra dago alkoholismoarekin arazoak izan dituzten familietan hazten diren nerabeek alkoholaren gehiegizko kontsumoa egiteko arrisku handiagoa daukatela: alde batetik, hazten ari diren inguruak dauzkan estimuluak direla eta (ikusten duten kontsumo-patroiak, alkoholaren ondoriozko kanpo-arazoak), eta bestetik, gene batzuek alkoholismoa garatzeko arrisku handiagoarekin eta garunaren morfologiaren ezberdintasunekin lotuta daudelako (azken horiek adikzioak garatzeko sentikortasun handituarekin erlazionatu dira) $[7,38]$.

\section{ONDORIOAK}

Funtzio neurokognitiboak ondo garatu daitezen, ezinbestekoa da garunaren hazkuntza egokia izatea. Eta nerabezaroan alkohola kontsumitzeak garunaren garapena eta egitura aldatzen ditu; gai grisaren bolumena murrizten du, bai eta gai zuriaren handitzea moteldu ere. Ondorioz, aipatu den bezala, nerabeen gaitasun kognitiboak kaltetuta agertzen dira: arreta, funtzio exekutatzaileak, lanerako memoria eta abar. Horretaz gain, jarrera inpultsiboen kontrolpean, sari-prosezamenduan eta lanerako oroimenean parte hartzen duten garun-atalen gainaktibazioa ikusten da, gaitasun horiek betetzeko ezintasunari aurre egiteko, alegia. Horrek indarra hartzen du, ja- 
kinda badirudiela funtzio horien erabateko berreskurapena gertatzea oso zaila dela.

Bestalde, nerabezaroan alkohola gehiegi kontsumitzeak heldutasunean alkoholarekiko menpekotasuna garatzeko arriskua handitzen du. EAEko alkoholaren kontsumoaren datuei erreparatuz, haren kontsumo-mailak murriztearen beharrean gaudela ondoriozta daiteke. Jakina da garatzen ari den garunak handitzen duela nerabeek duten arriskuak hartzeko eta bizipen berriak bilatzeko joerak, hala nola alkoholaren eta beste drogen erabilera. Joera horiek oinarri biologikoa dutela jakinda, beharrezkoa egiten da ulertzea edatea debekatzeak ez duela lortuko nerabeen abstinentzia; egokiena, ordea, izan liteke, alde batetik, haiei irakastea bizipen berriak izan ditzaketela baina modu osasuntsuago eta seguru batean, drogak erabili gabe; eta, bestetik, jakinaraztea zeintzuk diren alkohola edatearen ondorioak epe laburrean nahiz epe luzean. Alkoholaren erabilera egokia lortzeko, funtsezkoa da gazteek behar besteko informazioa izatea; izan ere, erabakia hartu aurretik horren ondorioak ikusarazten badira, erabaki arriskutsuak hartzeko joera jaisten dela ikusi da, agian gertaerei aurrea hartzeko gaitasun txikiagoa izategatik [53]. Interesgarria izango litzateke, prebentzio moduan, irakastea zeintzuk diren erabaki batzuen ondorioak, haiek hartu baino lehen.

\section{ESKER ONAK}

Amaia Núñez del Moralek Eusko Jaurlaritzako Hezkuntza sailaren Doktorego Aurreko Programaren laguntza du. Lan honen egileek Eusko Jaurlaritzaren (IT-1211-19) eta The European Foundation for Alcohol Research-aren (EA1819) diru-laguntzak jaso dituzte.

\section{BIBLIOGRAFIA}

[1] Management of Substance Abuse Team.World Health Organization. 2018. Global status report on alcohol and health 2018. Suitza.

[2] Eusko Jaurlaritzako Osasun Saila eta Eguía-Careaga Fundazioa. 2018. Adikzioei buruzko Euskadiko inkesta, 2017. Datuen aurrerapena. https:// www.euskadi.eus/contenidos/informacion/adicciones_euskadi_drogas/eu_ def/adjuntos/Encuesta-Adicciones-2017-Avance-Resultados_EUSK.pdf

[3] NUTT, D.J., KING, L.A., PHILLIPS, L.D. 2010. Drug harms in the UK: a multicriteria decision analysis. The Lancet, 376, 1558-65.

[4] MILLER J.W., NAIMI T.S., BREWER R.D., JONES S.E. 2017. Binge Drinking and Associated Health Risk Behaviors Among High School Students. Pediatrics, 119, 76-85.

[5] DEAS D. 2002. Comorbid Psychiatric Factors Contributing to Adolescent Alcohol and Other Drug Use. Alcohol research \& Health, 26, 116-121. 
[6] KRISTJANSSON AL, SIGFUSDOTTIR ID, ALLEGRANTE JP. 2013. Adolescent substance use and peer use: a multilevel analysis of cross-sectional population data. Subst. Abuse Treat Prev. Policy, 8, 1-10.

[7] JACOBUS J., TAPERT S.F. 2013. Neurotoxic Effects of Alcohol in Adolescence. Annu Rev Clin Psychol., 9, 703-21.

[8] DEGENHARDT L., O'LOUGHLIN C., SWIFT W., ROMANIUK H., CARLIN J., COFFEY C. et al. 2013. The persistence of adolescent binge drinking into adulthood: findings from a 15-year prospective cohort study. BMJ Open, 3, 1-11.

[9] HINGSON R.W., HEEREN T., WINTER M.R. 2006. Age at drinking onset and alcohol dependence: age at onset, duration, and severity. Arch. Pediatr. Adolesc. Med., 160, 739-46.

[10] COSTARDI J.V.V., NAMPO R.A.T., SILVA G.L., RIBEIRO M.A.F., STELLA H.J., STELLA M.B. et al. 2015. A review on alcohol: from the central action mechanism to chemical dependency. Rev. Asso.c Médica Bras., 61, 381-7.

[11] GRIFFITH C., LA FRANCE B. 2018. The Neural Effects of Alcohol. Med. Case Rep. Rev., 1, 1-3.

[12] ABRAHAO K.P., SALINAS A.G., LOVINGER D.M. 2017. Alcohol and the Brain: Neuronal Molecular Targets, Synapses, and Circuits. Neuron, 96, 1223-38.

[13] COSTARDI J.V.V., NAMPO R.A.T., SILVA G.L., RIBEIRO M.A.F., STELLA H.J., STELLA M.B., PINHEIRO MALHEIROS S.V. 2015. A review on alcohol: from the central action mechanism to chemical dependency. Rev. Assoc. Médica. Bras., 61, 381-7.

[14] OSCAR-BERMAN M., MARINKOVIĆ K. 2007. Alcohol: Effects on Neurobehavioral Functions and the Brain. Neuropsychol Rev., 17, 239-57.

[15] GILPIN N.W. 2008. Neurobiology of Alcohol Dependence. Neurobiol. Alcohol Depend., 31, 185-195.

[16] RAJMOHAN V., MOHANDAS E. 2007. The limbic system. Indian J. Psychiatry., 49,132-139.

[17] LABAR K.S., CABEZA R. 2006. Cognitive neuroscience of emotional memory. Nat. Rev. Neurosci., 7, 54-64.

[18] WRASE J, MAKRIS N, BRAUS DF, MANN K, SMOLKA MN, KENNEDY DN et al. 2008. Amygdala Volume Associated With Alcohol Abuse Relapse and Craving. Am. J. Psychiatry., 165, 1179-84.

[19] BINDER M.D., HIROKAWA N., WINDHORST U. 2009. Encyclopedia of Neuroscience. Springer Berlin Heidelberg, Berlin.

[20] PITEL A.L., SEGOBIN S.H., RITZ L., EUSTACHE F., BEAUNIEUX H. 2015. Thalamic abnormalities are a cardinal feature of alcohol-related brain dysfunction. Neurosci. Biobehav. Rev., 54, 38-45.

[21] MIALL RC. 2013. Neuroscience in the 21st Century: From Basic to Clinical. Springer, New York.

[22] MIQUEL M. 2016. Have we been ignoring the elephant in the room? Seven arguments for considering the cerebellum as part of addiction circuitry. Neurosc.i Biobehav. Rev. 60, 1-11. 
[23] SEGOBin S.H., CHÉTELAT G., BERRE A-P.L., LANNUZEL C., BOUDEHENT C., VABRET F. et al. 2014. Relationship Between Brain Volumetric Changes and Interim Drinking at Six Months in Alcohol-Dependent Patients. Alcohol. Clin. Exp. Res., 38, 739-48.

[24] UHL G.R., KOOB G.F., CABLE J. 2019. The neurobiology of addiction. Ann. N. Y. Acad. Sci., 1451, 5-28.

[25] SPEAR L.P. 2000. The adolescent brain and age-related behavioral manifestations. Neurosci. Biobehav. Rev., 24, 417-63.

[26] SPEAR L.P. 2018. Effects of adolescent alcohol consumption on the brain and behaviour. Nat. Rev. Neurosci., 19, 197-214.

[27] LEES B., MEREDITH L.R., KIRKLAND A.E., BRYANT B.E., SQUEGLIA L.M. 2020. Effect of alcohol use on the adolescent brain and behavior. Pharmacol. Biochem. Behav., 192, 1-27.

[28] STILES J., JERNIGAN T.L. 2010. The Basics of Brain Development. Neuropsychol. Rev., 20, 327-48.

[29] SPEAR L.P. 2013. Adolescent Neurodevelopment. J. Adolesc. Health., 52, 7-13.

[30] GIEDD J.N. 2004. Structural Magnetic Resonance Imaging of the Adolescent Brain. Ann. N. Y. Acad. Sci., 1021, 77-85.

[31] Bava S., Jacobus J., Thayer R.E., Tapert S.F. 2013. Longitudinal Changes in White Matter Integrity Among Adolescent Substance Users. Alcohol Clin. Exp. Res., 37,181-9.

[32] LEBEL C., GEE M., CAMICIOLI R., WIELER M., MARTIN W., BEAULIEU C. 2012. Diffusion tensor imaging of white matter tract evolution over the lifespan. NeuroImage., 60, 340-52.

[33] SMITH A.R., STEINBERG L., STRANG N., Chein J. 2015. Age differences in the impact of peers on adolescents' and adults' neural response to reward. Dev. Cogn. Neurosci., 11, 75-82.

[34] COOPER M.L. 1994. Motivations for alcohol use among adolescents: Development and validation of a four-factor model. Psychological Assessment, 6,117-28.

[35] CASEY B.J., JONES R.M. 2010. Neurobiology of the Adolescent Brain and Behavior: Implications for Substance Use Disorders. J. Am. Acad. Child. Adolesc. Psychiatry., 49, 1189-201.

[36] ERNST M. 2014. The triadic model perspective for the study of adolescent motivated behavior. Brain Cogn., 89, 104-11.

[37] HOOGENDAM J.M., KAHN R.S., HILLEGERS M.H.J., VAN BUUREN M., VINK M. 2013. Different developmental trajectories for anticipation and receipt of reward during adolescence. Dev. Cogn. Neurosci., 6, 113-24.

[38] CSERVENKA A., BRUMBACK T. 2017. The Burden of Binge and Heavy Drinking on the Brain: Effects on Adolescent and Young Adult Neural Structure and Function. Front. Psychol., 8, 1-13.

[39] SQUEGLIA L.M., TAPERT S.F., SULLIVAN E.V., JACOBUS J., MELOY M.J., ROHLFING T. et al. 2015. Brain Development in Heavy-Drinking Adolescents. Am. J. Psychiatry., 172, 531-42. 
[40] LUCIANA M., COLLINS P.F., MUETZEL R.L., LIM K.O. 2013. Effects of alcohol use initiation on brain structure in typically developing adolescents. Am. J. Drug Alcohol Abuse., 39, 345-55.

[41] TAPERT SF, PULIDO C, PAULUS MP, SCHUCKIT MA, BURKE C. 2004. Level of response to alcohol and brain response during visual working memory. J. Stud. Alcohol., 65, 692-700.

[42] TAPERT S.F., SCHWEINSBURG A.D., BARLETT V.C., BROWN S.A., FRANK L.R., BROWN G.G. et al. 2004. Blood oxygen level dependent response and spatial working memory in adolescents with alcohol use disorders. Alcohol Clin. Exp. Res., 28, 1577-86.

[43] SQUEGLIA L.M., PULIDO C., WETHERILL R.R., JACOBUS J., BROWN G.G., TAPERT S.F. 2012.Brain Response to Working Memory Over Three Years of Adolescence: Influence of Initiating Heavy Drinking. J. Stud Alcohol Drugs., 73, 749-60.

[44] CSERVENKA A., JONES S.A., NAGEL B.J. 2015. Reduced cerebellar brain activity during reward processing in adolescent binge drinkers. Dev. Cogn. Neurosci., 16, 110-20.

[45] DIAMOND A. 2013. Executive Functions. Annu. Rev. Psychol., 64, 135-68.

[46] LAWRENCE AJ, LUTY J, BOGDAN NA, SAHAKIAN BJ, CLARK L. 2009. Impulsivity and response inhibition in alcohol dependence and problem gambling. Psychopharmacology (Berl)., 207, 163-72.

[47] AMES S.L., WONG S.W., BECHARA A., CAPPELLI C., DUST M., GRENARD J.L. et al. 2014. Neural correlates of a Go/NoGo task with alcohol stimuli in light and heavy young drinkers. Behav. Brain Res., 274, 382-9.

[48] CAMPANELlA S., PEIGNEUX P., PETIT G., LALlEMAND F., SAEREMANS M., NOËL X. et al. 2013. Increased Cortical Activity in Binge Drinkers during Working Memory Task: A Preliminary Assessment through a Functional Magnetic Resonance Imaging Study. PLoS ONE, 8, 1-10.

[49] ADINOFF B. 2004. Neurobiologic Processes in Drug Reward and Addiction: Harv. Rev. Psychiatry., 12, 305-20.

[50] KREUSCH F., GOFFAUX V., SIEP N., HOUBEN K., QUERTEMONT E., WIERS R.W. 2015. Brain Activation Associated with Automatic Processing of Alcohol-Related Cues in Young Heavy Drinkers and Its Modulation by Alcohol Administration. Alcohol Clin. Exp Res., 39, 1957-66.

[51] BRUMBACK T., SQUEGLIA L.M., JACOBUS J., PULIDO C., TAPERT S.F., BROWN S.A. 2015. Adolescent heavy drinkers' amplified brain responses to alcohol cues decrease over one month of abstinence. Addict. Behav., 46, 45-52.

[52] MAHMOOD O.M., JACOBUS J., BAVA S., SCARLETT A., TAPERT S.F.2010. Learning and Memory Performances in Adolescent Users of Alcohol and Marijuana: Interactive Effects. J. Stud. Alcohol Drugs., 71, 885-94.

[53] WORBE Y., IRVINE M., LANGE I., KUNDU P., HOWELL N.A., HARRISON N.A. et al. 2014. Neuronal Correlates of Risk-Seeking Attitudes to Anticipated Losses in Binge Drinkers. Biol Psychiatry., 76, 717-24. 